\title{
Plant blindness and the implications for plant conservation
}

Running head: Plant blindness

Keywords: plant blindness; zoo chauvinism; public support; human dimensions of conservation; flora appreciation.

\section{Mung Balding}

Office of Environmental Programs, University of Melbourne, 221 Bouverie Street, Parkville 3010,

Australia

\section{Kathryn Williams*}

School of Ecosystem and Forest Sciences, University of Melbourne, 221 Bouverie Street, Parkville 3010, Australia, email kjhw@unimelb.edu.au

${ }^{*}$ Corresponding author.

This article has been accepted for publication and undergone full peer review but has not been through the copyediting, typesetting, pagination and proofreading process, which may lead to differences between this version and the Version of Record. Please cite this article as doi: 10.1111/cobi.12738.

This article is protected by copyright. All rights reserved. 


\section{Abstract}

Plant conservation initiatives lag behind efforts to promote animal species, receiving considerably less funding. This essay explores one potential reason for that bias: a tendency among humans to neither notice nor value plants in the environment. We assess evidence for 'plant-blindness' and conclude there are indeed biases in appreciation of plants, but that this bias is not inevitable. We evaluate research from psychology and anthropology to identify the psychological and cultural bases of 'plant blindness' and conclude that both perceptual and cultural factors shape the ways that people understand and value plants, and that conservation programs can therefore contribute to reducing this bias. Based on this analysis we argue that support for plant conservation may be garnered by strategies that promote identification and empathy with plants. We identify potential ways to achieve this, and argue the need for action research to understand the efficacy of those approaches.

Conservation initiatives are biased against plants and towards mammals and birds (Metrick \& Weitzman 1996; Martin-Lopez et al. 2011; Havens et al. 2014), particularly well-studied large-bodied mammal species (Sitas et al. 2009) with forward facing eyes (Smith et al. 2012). The extent of the conservation bias against plants is highlighted by US figures showing that "despite plants comprising the majority of the federal endangered species list (57\%), in 2011 they received less than $3.86 \%$ of federal endangered species expenditures" (Havens et al. 2014, p.8), a pattern repeated in other nations (Martin-Lopez et al. 2009; Laycock et al. 2011). Concurrent with this is a dramatic decline in botanical degree programs and courses, a major shortage of government employed botanists and chronic underfunding of plant conservation in relation to animal conservation (Kramer et al. 2010).

This article is protected by copyright. All rights reserved. 
The ongoing loss of plant diversity is neglected by politicians and the media and insufficient resources are allocated to reverse this trend (Cires et al. 2013).

While there are perhaps multiple reasons for this bias in funding and support, human appreciation of plants is likely to play a critical role. There is considerable evidence that human perspectives on species and ecosystems have direct implications for their conservation: landholders are more likely to manage remnant vegetation in positive ways where they express 'liking' for that vegetation (Williams \& Cary 2002) or feel a sense of connection with nature (Gosling \& Williams 2010); students are more likely to donate money to conserve species where they have empathy for that species (Berenguer 2007) and people are more likely to support conservation of species they find attractive (Knight 2007).

In this context, evidence that humans more readily detect, appreciate and support fauna compared with flora (Bozniak 1994; Uno 1994; Wandersee \& Schussler 2001) raises important challenges for plant species conservation. Evidence for 'plant-blindness' or 'zoocentrism' has been presented across a range of studies from the fields of plant biology, psychology and science education (Wandersee \& Schussler 2001; Hershey 2002; Lindemann-Matthies 2005; Clary \& Wandersee 2011), but the implications of this bias for conservation practice has been given little attention. In this essay we explore the evidence for this bias, as well as theoretical accounts of its psychological and cultural basis. We draw on this analysis to argue that plant appreciation can be promoted through programs that help people to identify and empathize with plants.

This article is protected by copyright. All rights reserved. 


\section{Assessing the evidence for plant-blindness}

Research concerning human-plant relationships is undertaken across a range of disciplines, and parallel lines of work present contrasting perspectives on the problem of plant-blindness: research from psychology and science education supports the plant-blindness hypotheses while research from anthropology points to societies holding strong bonds with plants. We argue that, considered as a whole, these bodies of research suggest that while preference for animals over plants is the norm in many societies, it is not inevitable.

A number of studies provide evidence that humans have higher preference as well as superior recall and visual detection of animals relative to plants. Baird and colleagues (1984) and Wandersee (1986) both surveyed secondary school students in the United States of America (USA) (sample sizes of 1855 and 136 students respectively) to test preferences for science topics and found clear preference for studying zoological topics ahead of botanical ones. Kinchin (1999) tested preferences of 162 students (United Kingdom resident) for specimens of an unfamiliar plant and animal in the classroom, and reported overwhelming preference for animal over plant specimens. Schussler and Olzak (2008) compared recall of pairs of equally familiar animals and plants among 124 psychology students and 203 botany students at a US university. Students first rated the attractiveness of plants and animals presented in images. Recall of these images was tested following a distraction task. Animal images were recalled significantly more than plant images, with this trend maintained for both botany and psychology students. Most recently, Balas and Momsen (2014) used experimental techniques to test whether 'plant blindness' is due to difficulties seeing plants in the first place. They proposed the phenomenon may reflect differences in visual memory, suggesting that plant images may be less robustly encoded than animal images. They tested this hypothesis making use of a

This article is protected by copyright. All rights reserved. 
phenomenon known as "attentional blink" (AB): when two images are briefly presented (10-50ms) in rapid succession, $A B$ refers to the phenomenon whereby detection of a first target image (T1) compromises ability to detect the second target image (T2) due to insufficient visual resources. Plant and animal images were used as T1 targets to measure the impact on detection of unrelated T2 images of water. Based on 640 trials with each of the 24 US female psychology students, the research demonstrated that detection of animals was significantly higher than plants and T1 false alarm rates for plants were significantly higher than animals. The authors concluded that plant images are harder to detect than animal images.

At the same time, there is a significant body of ethnographic research demonstrating that many individuals and social groups have strong bonds with plants, including some Aboriginal Australian, Native North American and Maori cultural groups (Descola 2009; Hall 2011). Many Indigenous Australians have a non-hierarchical kinship relationship with plants that recognizes human-plant difference but also a shared ancestry (Rose 1992). These kinship relationships have obligations of "responsibility, solidarity and care" for plants while recognizing the necessity of plant use whereby "killing and harm takes place within structure, balanced, and reciprocal relationships" (Hall 2011, p. 112). People belong to clans based on their lines of descent, while particular plant and animal species are "assigned to clans due to the actions of the Spirit Ancestors" (Bradley et al. 2006, p. 10). Thus, an individual's kinship relationship with certain plant species will differ depending upon which clan the individual belongs to and this kinship will be used in relating to the plant species. For example, in the Yanyuwa community, Minnie a-Wulbulinimara identifies a pandanus palm as "my mother's mother's brother" and a grey mangrove as "my husband" (Bradley et al. 2006, p. 9). A similar relationship with plants is practiced by Native North Americans and Maori people who also

This article is protected by copyright. All rights reserved. 
recognize kinship between humans and plants, based upon a shared heritage (Hall 2011). Greater affiliation with plants can exist even in contexts where animals are in plentiful supply. This is demonstrated by the Ankave, in Papua New Guinea, who "draw close connection between trees and humans" through use in ritual and everyday settings (Bonnemere 1998, p. 127). For example, the red juice of Pandanus conoideus has an analogical relationship with blood (considered the main agent of bodily growth) that informs practices related to maturation, health, procreation and male initiation (Bonnemere 1998). Numerous other social groups in North and South America, Siberia, South-East Asia maintain all sorts of human-like relationships with plants: friendship, exchange or seduction (Descola 2009).

These different lines of research may appear contradictory, but a more coherent picture emerges when differences across discipline, purpose, methods and populations of interest are considered. Evidence demonstrating differential preference and recall for animals over plants is grounded in psychological approaches that aggregate trends at a population level and set out to test specific biases in perception. Evidence of strong affiliation with plants is grounded in intensive fieldwork seeking to provide an in-depth understanding of practices within a particular community or social group. Taken together, we interpret these two bodies of work as: (1) providing evidence of general perceptual biases for animals compared with plants, suggesting that 'plant-blindness' may indeed be one factor underpinning biases toward conservation funding and action for animal species; and (2) providing evidence that such bias is not inevitable since strong bonds with plants are clearly possible within many social groups. This latter point is critical: conservation programs may be able to play a role in challenging plant-blindness.

This article is protected by copyright. All rights reserved. 


\section{Possible reasons for differential appreciation of plants and animals}

The potential to successfully challenge plant-blindness depends partly on the causes for the biases observed: are these factors open to change? In this section we assess potential psychological and social forces that contribute to plant blindness or zoo-centrism among many social groups. We argue that while plant-blindness has a foundation in biologically-based patterns of perception and cognition, cultural factors play a significant role in determining whether a given individual notices and values plants.

Some researchers attribute 'plant blindness' primarily to biologically-based visual, cognitive and functional processes shared across all humans. Wandersee \& Schussler (2001) suggest that because plants generally do not move, grow in close proximity, often have uniform colour, and so blend together visually, they are simply 'not seen'. Evolutionary psychologists have suggested that greater attendance to animals over plants may be related to the functional significance of animals for human survival. The 'animate monitoring hypothesis' suggested that evidence showing humans detect changes in animals and humans more than plants may be due to our ancestral huntergatherers' need to monitor animals that may eat or harm humans or provide a food source (New et al. 2007). Humans have historically had a higher reliance on animal-based foods than plants (Cordain et al. 2000) and it is proposed that this modern trait of greater attention to animals than plants is ancestrally derived (New et al. 2007).

These hypotheses are consistent with the patterns of visual detection biases reported by Balas and Momsen (2014). They are also consistent with evidence that, observed across childhood development, there is a tendency for children to recognise non-human animals as living earlier than they recognise plants as living. Young children's conceptions of the natural world are initially

This article is protected by copyright. All rights reserved. 
anthropocentric (Carey 1985) and they struggle with the concept of plants being alive (Richards \& Siegler 1984; Richards \& Siegler 1986; Bebbington 2005). By around 10 years old, most children have expanded their notion of living things (Carey 1985) from people to animals and finally plants (Yorek et al. 2009). Motion has been shown to be a determinant of judging whether a stimulus is alive (Richards \& Siegler 1986), giving further weight to this interpretation of the data.

Other researchers highlight social and cultural factors that may contribute to biases within social groups. Some researchers have attributed poor knowledge of plants (Bebbington 2005; Gatt et al. 2007; Fancovicova \& Prokop 2011) to the focus of biological training. Uno (1994) found high school biology textbooks devoted only $14 \%$ of their chapters and $20 \%$ of their laboratory exercises to plants and botanical topics. The term 'zoochauvinist' was coined to indicate the dominance of an animal focus by biology teachers (Bozniak 1994). Others suggest that biases against plants reflect much broader worldviews within some cultures and societies at particular points in time. For example, Hall argues that the "zoocentrism found in Western society pervades all cultural ideas and actions toward the plant kingdom" (Hall 2011, p. 6). Plumwood (1993) and Hall (2011) argue that this bias has its foundations in a worldview which positions humans at the peak of a hierarchy: animals serving man, plants serving animals and the inanimate serving plants. In Western society, this construct can be traced from Plato, Aristotle and the early rationalists, through Christian and Cartesian thought to the present day (Plumwood 1993, Hall 2011). However, evidence exists of earlier Western societies having a different relationship with flora. The pagans of pre-Christian Europe recognised plants as kin and demonstrated a relationship of care, solidarity and responsibility much in common with animistic cultures (Hall 2011).

This article is protected by copyright. All rights reserved. 
Research to date does not allow precise statements regarding pathways to plant-blindness, but it is likely that both biological and cultural factors shape human-plant relationships. If biologically-based factors make it more difficult for humans generally to detect, recall and appreciate plants, an individual's perception of plants will also be profoundly influenced by the social and cultural contexts they inhabit (Fischer et al. 2011). Cultural processes such as language and practices affect the ways that people develop and organize knowledge of their environments, as well as the world views and values they express in relation to other species (Bang et al. 2007). If immersed in a plantaffiliated culture, the individual will experience language and practices that enhance capacity to detect, recall and value plants, something less likely to occur in zoocentric societies. Plant conservation programs therefore have a role to play in promoting experiences, language and practices that challenge zoocentric assumptions common to many societies.

\section{Opportunities to challenge zoocentrism}

If the observed differential appreciation and support for animal and plant conservation is not inevitable, how can conservation practitioners act to challenge zoocentrism? Psychological studies have consistently shown that education or information alone typically does not result in increased conservation behavior (McKenzie-Mohr et al. 2012). Conservation programs will need more innovative approaches. In this section we evaluate three interrelated and promising lines of research to suggest broad strategies for promoting plant conservation.

A unifying theme across this analysis is the importance of promoting opportunities for people to connect with plants emotionally or cognitively. This is grounded in emerging research on

This article is protected by copyright. All rights reserved. 
'connectedness theory' (see Tam 2013; Restall \& Conrad 2015 for overview) which suggests that willingness to address environmental issues is related to "the degree to which [a person] includes other people and nature within his or her cognitive representations of self" (Schultz 2000, p. 393). There is increasing evidence that people who view themselves as part of nature are more likely to exhibit pro-environmental concern and behaviour (Schultz 2000; Mayer \& Frantz 2004; Berenguer 2007; Davis et al. 2009; Gosling \& Williams 2010). We propose that a person's capacity to connect with plants - to perceive 'human-like' traits in plants, to identify or empathize with plants - may increase inclusion of plants within sense of self, and thus appreciation of plant species.

\section{Identification with plants}

Support for conservation of species generally is partly explained by presence of traits that are 'human-like'. A number of studies have identified characteristics of animal species that are linked with public support for conservation: aesthetic appeal (Knight 2007); size (Kellert 1996); phylogenetical similarity to humans (Samples 1986; Kellert 1996); capacity for feeling, thought and pain (Kellert 1996); and ecological importance and rarity (Czech et al. 1998). Across these studies, 'human-like' traits - including size, phylogenetical similarly and sentience - explain a significant proportion of variation in support for different animal species. Similarly, preference for animals over plants has been shown to be due to human-like traits of animals: such as movement (Wandersee 1986; Kinchin 1999), capacity to eat, having eyes and faces, communicating with sound and the lack of these characteristics in plants (Wandersee 1986). This area of research points to the potential for conservation programs to use strategies that highlight the ways that plants are in fact similar to humans.

This article is protected by copyright. All rights reserved. 
The likely success of such approaches is supported by the observation that cultural groups exhibiting clear affiliation with plants, appear to have a relationship with plants via the attribution of shared or 'human-like' traits to plants. For example, the coconut palm plays a significant role within the lives of the island inhabitants of Nusa Penida near Bali (Giambelli 1998). The tree and its fruit mark peoples' lives from birth to death; a tree planted by a man for his child's first tooth ritual in effect becomes the child's alter ego. The tree's life span then parallels humans and in rituals is clothed, presented food and addressed as 'grandmother'. Numerous terms apply equally to the coconut palm and the human body (Giambelli 1998). Common in the Amazon, among the Indians of Subarctic Canada and the Inuit is the belief that plants and animals are persons possessing a soul identical to the one they possess, thus allowing social relations with them (Descola 2009). A range of cultures and subcultures can provide insight and ideas for supporting greater flora appreciation in a Western context "without fetishizing or appropriating Indigenous people and their culture of connection" (Rose 1999, p. 182).

\section{Empathy with plants}

There is increasing evidence that connection with nature can change through the practice of empathy (Schultz 2000). For example, Berenguer (2007) conducted an experiment demonstrating that empathizing with nature can increase concern and practical support for conservation of species. Participants were randomly assigned to view photographs of a dead bird on a beach covered in oil, or an area with eight trees that had been cut down and were lying on the ground. Half the participants were assigned to a low empathy condition and were instructed to remain detached and objective while viewing the trees or bird. Remaining participants were instructed to empathize with the bird or trees, imagining how the bird or tree felt and the impact of this experience. Participants

This article is protected by copyright. All rights reserved. 
who empathized with the other species not only expressed greater concern for its welfare, but recommended a higher level of funding allocation to environmental programs. Interestingly in both high and low empathy conditions, concern and financial allocations were lower for trees than for birds. Berenguer notes: "People may identify more closely, at a cognitive level, with the bird than with the tree, so the level of inclusiveness will be higher in the case of the bird" (Berenguer 2007, p. 281).

While animal advocacy campaigns often appear designed to trigger empathy with threatened species, intentional use of connectedness or empathy-based strategies is relatively rare in conservation programs (Zylstra et al. 2014; Restall \& Conrad 2015). One potential exception is the Council of All Beings program, which uses rituals and role playing in which participants give voice to the concerns of non-human forms including animals, trees, water and rocks (Bragg 1996). The effectiveness of this program for people with limited existing commitment to nature conservation is unclear.

\section{(Appropriate) anthropomorphization of plants}

Anthropomorphism - attributing human characteristics to nature - is commonly used in environmental discourse (Epley et al. 2007; Tam et al. 2013) and may be a potent factor in strengthening public appreciation of plant species. Recent studies show that people anthropomorphize to varying degrees, while their tendency to anthropomorphize 'nature' predicts moral care toward nonhumans in nature (Waytz et al. 2010). Anthropomorphism of nature enhances connectedness to nature (Tam et al. 2013) and action efficacy which mediate the relationship

This article is protected by copyright. All rights reserved. 
between anthropomorphism and self-reported conservation behavior (Tam 2014). Numerous authors have suggested the use of anthropomorphized narratives as a conservation tool in increasing the charismatic representation and empathy for individual species (Chan 2012; RootBernstein \& Armesto 2013; Root-Bernstein et al. 2013), but we found little evidence that anthropomorphism is used to promote plant conservation.

There is reason for caution in suggesting anthropomorphism-based strategies for promoting plant conservation. Hall (2011) has argued there are dangers in suggesting similarities between humans and other species where these similarities are non-existent. Wynne (2007) argues that anthropomorphizing animal behavior is an outdated Darwinian concept that has no place in contemporary psychology. Although clearly a potential conservation tool, careful consideration needs to be given to current human interactions with the individual species and the anthropomorphic projections ascribed (Karlsson 2012; Root-Bernstein et al. 2013) as negative conservation outcomes are also possible (Root-Bernstein et al. 2013).

Employment of these three broad strategies would be further strengthened if grounded in direct experience of plants. There is evidence that direct experience can influence plant related attitudes and behaviors. Experiential outdoor education programs can have a positive effect on students' environmental attitude generally (Bogner 1998; Skelley \& Zajicek 1998; Bogner \& Wiseman 2004; Fancovicova \& Prokop 2011; Lieflander \& Bogner 2014) as well as broad connection to nature (Ernst \& Thiemer 2011). Children participating in outdoor nature programs involving plants will increase their appreciation and knowledge of plants (Lindemann-Mathies 2005; Fancovicova \& Prokop 2011) and active gardening during childhood fosters positive adult perceptions of the social and intrinsic values of trees (Lohr \& Pearson-Mims 2005). A number of plant-focused education programs have

This article is protected by copyright. All rights reserved. 
been shown to have positive impact on children's engagement with plants, although impact on support for plant conservation has not been explored. Notable Australian examples include the Royal Botanic Gardens Melbourne Children's Garden designed to foster children's delight in nature and passion for plants (Barley 2009) and the Stephanie Alexander Kitchen Garden Program which involves children at over 800 Australian primary schools in establishing an organic garden and the harvesting and cooking of produce (Stephanie Alexander Kitchen Garden Foundation 2015).

Thought needs to be given to the kinds of activities undertaken in direct experience programs. For example, research has shown householders view their gardens as "part of the domestic world" (Clayton 2007, p. 223), an ecology of prestige (Grove et al. 2006) with sustainable practice of little concern (Clayton 2007). A survey of 466 US homeowners revealed only 3.4\% believed creating wildlife habitat and conserving natural resources was central to the meaning of the term 'gardener' (Kiesling \& Manning 2010). Gardening-based strategies are unlikely to effectively promote plant conservation unless such human-centric assumptions are challenged.

\section{Implications for plant conservation}

Our analysis points to a number of practical ways to implement plant conservation programs grounded in promotion of identification, empathy and anthropomorphism with plants. The likely effectiveness of these strategies is supported by theoretical and empirical evidence, however practical application and evaluation is scant. We call for action research and adaptive management approaches to better understand their practical efficacy.

This article is protected by copyright. All rights reserved. 


\section{Enable direct experience of plants that draws attention to individual plants and species:}

Fostering capacity to look beyond the 'amorphous forest' and promoting discovery of individual plant species may be a critical point in creating empathic connection with plants (Wandersee \& Schussler 2001). There are many ways this might be achieved that extend well beyond the taxonomic approaches typically used in botanical training: gardening to emphasize diverse functions of plants, drawing activities to promote close observation, exploration of plant movement or highlighting the human-like traits of individual plant species.

Emphasize evidence-based similarities between plants and humans: There is increasing scientific evidence of 'human-like' traits of flora, such as being alive, having intentional motion, food uptake, are sexually active, communicate with neighbors (see Gagliano 2013 for communication overview) and recognition and favoring of kin over strangers (Dudley \& File 2007; Murphy \& Dudley 2009). Importantly, contemporary scientific understandings of plants should be integrated in primary and secondary school curricula given past evidence of biases against plants in school texts (Uno 1994).

Use creative activities to promote empathy with plants: Collaborations between plant scientists and artists may play a crucial role in promoting positive emotional connections with plants (Jacobson et al. 2007; Curtis 2011). Creative activities such as story writing, drawing, imagining and role playing and rituals, including anthropomorphism, can encourage active empathy with other species including plants (Bragg 1996; Osbourne 2009).

This article is protected by copyright. All rights reserved. 
Humans are inextricably linked to conservation agendas yet still remain a relatively neglected focus in conservation biology (Mascia et al. 2003; Schultz 2011). While theoretical and empirical research suggests the strategies identified here are likely to promote support for plant conservation, the paucity of practical application of these strategies currently prevents effective evaluation (Zylstra et al. 2014; Restall \& Conrad 2015). The urgency for action on redressing imbalances between plant and animal conservation is however clear. In the face of this challenge, we call for new collaborations between conservation practitioners and social scientists to develop action research enabling implementation and systematic evaluation of approaches grounded in identification and empathy with plants.

\section{Literature Cited}

Baird, J. H., R. Lazarowitz, and V. Allman. 1984. Science choices and preferences of middle and secondary school students in Utah. Journal of Research in Science Teaching 21:47-54.

Balas, B., and J. L. Momsen. 2014. Attention "blinks" differently for plants and animals. CBE Life Science Education. 13:437-443.

Bang, M., D. L. Medin, and S. Atran. 2007. Cultural mosaics and mental models of nature. Proceedings of the National Academy of Sciences. 104:13868-13874.

Barley, R. (2009). A landscape for children: the lan Potter Foundation Children's Garden at the Royal Botanic Gardens Melbourne. Australasian Parks and Leisure. 12:15-17.

Bebbington, A. 2005. The ability of a-level students to name plants. Journal of Biological Education. 39:62-67.

This article is protected by copyright. All rights reserved. 
Berenguer, J. 2007. The effect of empathy in proenvironmental attitudes and behaviors.

Environment and Behavior. 39:269-283.

Bogner, F. X. 1998. The influence of short-term outdoor ecology education on long-term variables of environmental perspective. The Journal of Environmental Education. 29:17-29.

Bogner, F. X., and M. Wiseman. 2004. Outdoor ecology education and pupils' environmental perception in preservation and utilization. Science Education International. 15: 27-48.

Bonnemere, P. 1998. Trees and people: some vital links. Tree products and other agents in the life cycle of the Ankave-Anga of Papua New Guinea. Pages 113-131 in L. Rival, editor. The social life of trees: anthropological perspectives on tree symbolism. Berg Publishing, Oxford, UK.

Bozniak, E. C. 1994. Challenges facing plant biology teaching programs. Plant Science Bulletin. 40: 4246.

Bradley, J., M. Holmes, D. N. Marrngawi, A. I. Karrakayn, J. M. Wuwarlu, and I. Ninganga. 2006.

Yumbulyumbulmantha ki-Awarawu - All kinds of things from Country: Yanyuwa ethnobiological classification. Aboriginal and Torres Strait Islander Studies Unit Research Report Series, no. 6.

Bragg, E. A. (1996). Towards ecological self: Deep ecology meets constructionist self-theory. Journal of Environmental Psychology. 16: 93-108.

Carey, S. 1985. Conceptual change in childhood. MIT Press, Cambridge, MA.

Chan, A. A. Y. H. 2012. Anthropomorphism as a conservation tool. Biodiversity and Conservation. 21:1889-1892.

This article is protected by copyright. All rights reserved. 
Cires, E., Y. De Smet, C. Cuesta, P. Goetghebeur, S. Sharrock, D. Gibbs, S. Oldfield, A. Kramer, and M. Samain. 2013. Gap analyses to support ex situ conservation of genetic diversity in Magnolia, a flagship group. Biodiversity and Conservation. 22:567-590.

Clary, R., and J. H. Wandersee. 2011. Our human-plant connection. Science Scope. 34(8): 32-37.

Clayton, S. 2007. Domesticated nature: motivations for gardening and perceptions of environmental impact. Journal of Environmental Psychology. 27:215-224.

Cordain, L., J. Brand Miller, S. B. Eaton, N. Mann, S. H. Holt, and J. D. Speth. 2000. Plant-animal subsistence ratios and macronutrient energy estimations in worldwide hunter-gatherer diets. American Journal of Clinical Nutrition. 71:682-692.

Curtis, D. J. 2011. Using the arts to raise awareness and communicate environmental information in the extension context. The Journal of Agricultural Education and Extension. 17:181-194.

Czech, B., P. R. Krausman, and R. Borkhataria. 1998. Social construction, political power, and the allocation of benefits to endangered species. Conservation Biology. 12:1103-1112.

Davis, J. L., J. D. Green, and A. Reed. 2009. Interdependence with the environment: commitment, interconnectedness and environmental behavior. Journal of Environmental Psychology. 29:173-180. Descola, P. 2009. Human natures. Social Anthropology. 17:145-157.

Dudley, S. A., and A. L. File. 2007. Kin recognition in an annual plant. Biology Letters. 3:435-438.

Epley, N., A. Waytz, and J. T. Cacioppo. 2007. On seeing human: a three factor theory of anthropomorphism. Psychological Review. 114:864-886.

Ernst, J., and S. Theimer. 2011. Evaluating the effects of environmental education programming on connectedness to nature. Environmental Education Research. 17:577-598.

This article is protected by copyright. All rights reserved. 
Fancovicova, J., and P. Prokop. 2011. Plants have a chance: outdoor educational programmes alter students' knowledge and attitudes towards plants. Environmental Education Research. 17:537-551.

Fischer, A., F. Langers, B. Bednar-Friedl, N. Geamana, and K. Skogen. 2011. Mental representations of animal and plant species in their social contexts: Results from a survey across Europe. Journal of Environmental Psychology. 31:118-128.

Gagliano, M. 2013. Green symphonies: a call for studies on acoustic communication in plants. Behavioral Ecology. 24:789-796.

Gatt, S., S.D. Tunnicliffe, K. Borg, and K. Lautier. 2007. Young Maltese children's ideas about plants. Journal of Biological Education. 41:117-121.

Giambelli, R. A. 1998. The coconut, the body and the human being. Metaphors of life and growth in Nusa Penida in Bali. Pages 133-157 in L. Rival, editor. The social life of trees: anthropological perspectives on tree symbolism. Berg Publishing, Oxford, UK.

Gosling, E., and K. J. H. Williams. 2010. Connectedness to nature, place attachment and conservation behaviour: testing connectedness theory among farmers. Journal of Environmental Psychology. 30:298-304.

Grove, J. M., A. R. Troy, J. P. M. O'Neil-Dunne, W. R. Burch Jr., M. L. Cadenasso, and S. T. A. Pickett. 2006. Characterization of households and its implications for the vegetation of urban ecosystems. Ecosystems. 9:578-597.

Hall, M. 2011. Plants as persons: a philosophical botany. State University of New York Press, Albany. Havens, K., A. T. Kramer, and E. O. Guerrant Jr. 2014. Getting plant conversation right (or not): the case of the United States. International Journal of Plant Sciences. 175:3-10.

This article is protected by copyright. All rights reserved. 
Hershey, D. 2002. Plant Blindness: "We have met the enemy and he is us". Plant Science Bulletin. 48: $78-84$

Jacobson, S. K., M. D. Mcduff, and M. C. Monroe. 2007. Promoting conservation through the arts: outreach for hearts and minds. Conservation Biology. 21:7-10.

Karlsson, F. 2012. Critical anthropomorphism and animal ethics. Journal of Agricultural and Environmental Ethics. 25:707-720.

Kellert, S. 1996. The value of life: biological diversity and human society. Island Press, Washington DC.

Kiesling, F. M., and C. M. Manning. 2010. How green is your thumb? Environmental gardening identity and ecological gardening practices. Journal of Environmental Psychology. 30:315-327.

Kinchin, I. M. 1999. Investigating secondary-school girls' preferences for animals or plants: a simple 'head-to-head' comparison using two unfamiliar organisms. Journal of Biological Education. 33:9599.

Knight, A. J. 2007. "Bats, snakes and spiders, Oh my!" How aesthetic and negativistic attitudes, and other concepts predict support for species protection. Journal of Environmental Psychology. 28:94103.

Kramer, A. T., B. Zorn-Arnold, and K. Havens. 2010, Assessing botanical capacity to address grand challenges in the United States. Available from http://www.bgci.org/usa/bcap (accessed September 2014).

This article is protected by copyright. All rights reserved. 
Laycock, H. F., D. Moran, J. C. R. Smart, D. G. Raffaelli, and P. C. L. White. 2011. Evaluating the effectiveness and efficiency of biodiversity conservation spending. Ecological Economics. 70:17891796.

Lieflander, A. K., and F. X. Bogner. 2014. The effects of children's age and sex on acquiring proenvironmental attitudes through environmental education. The Journal of Environmental Education. 45:105-117.

Lindemann-Mathies, P. 2005. 'Loveable' mammals and 'lifeless' plants: how children's interest in common local organisms can be enhanced through observation of nature. Journal of Science Education. 27:655-677.

Lohr, V. I., and C. H. Pearson-Mims. 2005. Children's active and passive interactions with plants influence their attitudes and action toward trees and gardening as adults. HortTechnology. 15:472476.

Martin-Lopez, B., C. Montes, L. Ramirez, and J. Benayas. 2009. What drives policy decision-making related to species conservation? Biological Conservation. 142:1370-1380.

Martin-Lopez, B., J. A. Gonzalez, and C. Montes. 2011. The pitfall-trap of species conservation priority setting. Biodiversity and Conservation. 20:663-682.

Mascia, M. B., J. P. Brosius, T. A. Dobson, B. C. Forbes, L. Horowitz, M. A. McKean, and N. J. Turner. 2003. Conservation Biology. 17:649-650.

Mayer, F. S., and C. M. Frantz. 2004. The connectedness to nature scale: a measure of individuals' feeling in community with nature. Journal of Environmental Psychology. 24:503-515.

This article is protected by copyright. All rights reserved. 
McKenzie-Mohr, D., N. Lee, P. W. Schultz, and P. Kotler. 2012. Social marketing to protect the environment: what works. Sage, Thousand Oaks, California.

Metrick, A., and M. L. Weitzman. 1996. Patterns of behavior in endangered species preservation. Land Economics. 72:1-16.

Murphy, G. P., and S. A. Dudley. 2009. Kin recognition: competition and cooperation in Impatiens (Balsaminaceae). American Journal of Botany. 96:1900-1996.

New, J., L. Cosmides, and J. Tooby. 2007. Category-specific attention for animal reflects ancestral priorities, not expertise. Proceedings of the National Academy of Sciences 104: 16598-16603.

Osbourne, A. 2009. A meeting place: the science, art and writing initiative. Current Science.

97:1547-1554.

Plumwood, V. 1993. Feminism and the mastery of nature. Routledge, London, UK.

Restall, B., and E. Conrad. 2015. A literature review of connectedness to nature and its potential for environmental management. Journal of Environmental Management. 159:264-278.

Richards, D. D., and R. S. Siegler. 1984. The effects of task requirements on children's life judgments. Child Development. 55:1687-1696.

Richards, D. D., and R. S. Siegler. 1986. Children's understanding of the attributes of life. Journal of Experimental Child Psychology. 42:1-22.

Root-Bernstein, M., and J. Armesto. 2013. Selection and implementation of a flagship fleet in a locally undervalued region of high endemicity. AMBIO. 42:776-787.

This article is protected by copyright. All rights reserved. 
Root-Bernstein, M., L. Douglas, A. Smith, and D. Verissimo. 2013. Anthropomorphized species as tools for conservation: utility beyond prosocial, intelligent and suffering species. Biodiversity and Conservation. 22:1577-1589.

Rose, D. 1992. Dingo makes us human: life and land in an Aboriginal Australian culture. Cambridge University Press, Cambridge, UK.

Rose, D. 1999. Indigenous ecologies and an ethic of connection. Pages 175-187 in N. Low, editor. Global ethics and environment. Routledge, London.

Samples, K. C., J. A. Dixon, and M. M. Gowen. 1986. Information disclosure and endangered species valuation. Land Economics. 62:306-312.

Schultz, P. W. 2000. Empathizing with nature: the effects of perspective taking on concern for environmental issues. Journal of Social Issues. 56:391-406.

Schultz, P. W. 2011. Conservation means behavior. Conservation Biology. 25:1080-1083.

Schussler, E. E., and L. A. Olzak. 2008. It's not easy being green: student recall of plant and animal images. Journal of Biological Education. 42:112-119.

Sitas, N., J. E. M. Baillie, and N. J. B. Isaac. 2009. What are we saving? Developing a standardized approach for conservation action. Animal Conservation. 12:231-237.

Skelley, S. M., and J. M. Zajicek. 1998. The effect of an interdisciplinary garden program on the environmental attitudes of elementary school students. HortTechnology. 8:579-583.

Smith, R. J., D. Verissimo, N. J. B. Isaac, and K. E. Jones. 2012. Identifying cinderella species: uncovering mammals with conservation flagship appeal. Conservation Letters. 5:205-212.

This article is protected by copyright. All rights reserved. 
Stephanie Alexander Kitchen Garden Foundation. 2014. Melbourne, Australia. Available from http://www.kitchengardenfoundation.org.au/content/pleasurable-food-education

(accessed October 2015).

Tam, K. P. 2013. Concepts and measures related to connection to nature: similarities and differences. Journal of Environmental Psychology. 34:64-78.

Tam, K. P., S. L. Lee, and M. M. Chao. 2013. Saving Mr. Nature: Anthropomorphism enhances connectedness to and protectiveness toward nature. Journal of Experimental Social Psychology. 49:514-521.

Tam, K. P. 2014. Anthropomorphism of nature and efficacy in coping with the environmental crisis. Social Cognition. 32:276-296.

Uno, G. E. 1994. The state of precollege botanical education, The American Biology Teacher. 56:263267.

Wandersee, J. H. 1986. Plants or animals - which do junior high school students prefer to study? Journal of Research in Science Teaching. 23:415-426.

Wandersee, J. H., and E. E. Schussler. 2001. Toward a Theory of Plant Blindness. Plant Science Bulletin. 47: 2-7.

Waytz, A., J. Cacioppo, and N. Epley. 2010. Who sees human? The stability and importance of individual differences in anthropomorphism. Perspectives on Psychological Science. 5:219-232.

Williams, K. J. H., and J. Cary. 2002. Landscape preferences, ecological quality, and biodiversity protection. Environment and Behavior. 34:257-274.

This article is protected by copyright. All rights reserved. 
Wynne, C. D. L. 2007. What are animals? Why anthropomorphism is still not a scientific approach to behavior. Comparative Cognition \& Behavior Reviews. 2:125-135.

Yorek, M., M. Sahin, and H. Aydin. 2009. Are animals 'more alive' than plants? Animisticanthropocentric construction of life concept. Eurasia Journal of Mathematics, Science \& Technology Education. 5:369-378.

Zylstra, M. J., A. T. Knight, K. J. Esler, and L. L. Le Grange. 2014. Connectedness as a core conservation concern: an interdisciplinary review of theory and a call for practice. Springer Science Reviews. DOI: 10.1007/s40362-014-0021-3.

This article is protected by copyright. All rights reserved. 


\section{University Library}

\section{- M M I E E R VA A gateway to Melbourne's research publications}

Minerva Access is the Institutional Repository of The University of Melbourne

Author/s:

Balding, M;Williams, KJH

Title:

Plant blindness and the implications for plant conservation

Date:

2016-12-01

Citation:

Balding, M. \& Williams, K. J. H. (2016). Plant blindness and the implications for plant conservation. CONSERVATION BIOLOGY, 30 (6), pp.1192-1199. https://doi.org/10.1111/ cobi. 12738 .

Persistent Link:

http://hdl.handle.net/11343/291916 